\title{
Minimally Invasive Spinous Process Splitting Approach for Management of Lumbar Canal Stenosis
}

\author{
Ali Mohammad AlGioushy, Mohammad Abd Almonem Negm, Mohammad Abd EIBaset Abd ElHakim \\ Department of Orthopedic Surgery, Faculty of Medicine, Al-Azhar University \\ Corresponding author: Mohammad Abd ElBaset Abd ElHakim, Mobile: 01147458147, \\ Email: dr.m.abdelbaset89@gmail.com
}

\begin{abstract}
Background: for years, the gold standard treatment of symptomatic lumbar canal stenosis refractory to conservative management is a facet preserving laminectomy. However, it has been suggested that extensive resection of the posterior bone, posterior ligaments and muscular structures led to increase postoperative pain, perioperative blood loss, complications and length of hospital stay. More recently, various authors have recommended surgical techniques that preserve posterior midline structures (i.e. spinous processes, vertebral arches, interspinous and supraspinous ligaments), as removal of these structures may contribute to instability after surgery. Objective: the purpose of our prospective study is to evaluate the surgical outcome of minimally invasive spinus process splitting approach in the treatment of lumbar canal stenosis.

Patients and Methods: this prospective study included 20 patients that were operated in Al Azhar University Hospitals in the period between January 2017 and March 2018 via minimally invasive spinus process splitting approach in the lumbar canal senosis. Pre- and postoperatively disability and pain scores were measured by using the Oswestry Disability Index (ODI) and Visual Analog Score (VAS). Results: our statistical results revealed that there was a statistically significant difference in the outcome between pre and postoperative after follow up period of 12 months regarding VAS for back pain and leg pain, postoperative ODI changes were significantly better. There was a significant decrease regarding operation time and postoperative hospital stay, blood loss and postoperative pain. Conclusion: so, the relevance of preservation of the posterior midline structures should be clarified in further studies.
\end{abstract}

Keywords: lumbar canal stenosis, decompression surgery, minimally invasive spinus process splitting approach.

\section{INTRODUCTION}

One of the most useful definitions of lumbar canal stenosis since its description is being a disproportion in the spinal canal between the size of the neural elements and the space available. Compression of the thecal sac and its neural contents can cause pain and neural symptoms ${ }^{(1)}$.Degenerative spinal stenosis is part of the aging process, and predicting who will be affected is not possible. No clear correlation is noted between the symptoms of stenosis and race, occupation, sex, or body type. The degenerative process can be managed, but it cannot be prevented by diet, exercise, or lifestyle ${ }^{(2)}$.Lumbar stenosis is the result of lumbar spine degeneration and loss of disc elasticity as well as disc herniation, facet hypertrophy, spur formation, spondylosis, thickening of yellow ligament and spondylolisthesis, all impinging on the spinal canal and intervertebral foramen. It can be categorized according to the anatomic area of the spine affected into central or lateral stenosis

The surgical aim of treatment for symptomatic lumbar canal stenosis is relief of symptoms by adequate neural decompression while, preserving much of the anatomy and the biomechanical function of the lumbar spine ${ }^{(3)}$.The concept of classic open decompressive lumbar laminectomy for the treatment of spinal stenosis dates back to 1893 when the procedure was performed by Lane. It is one of the most commonly performed procedures which can be done alone or along with a variety of other procedures such as foraminotomies for affected roots and partial or complete facetectomies. The extent of decompression should be determined according to each affected anatomical site ${ }^{(4)}$. Despite affording a wide decompression, laminectomy or "unroofing" of the spinal canal, open decompression can cause destruction or impairment, insufficiency of the pars interarticularis or facet joints and the posterior midline ligaments such as the supra- and interspinous ligaments lose their original attachments when the spinus processes are removed. Such intraoperative damage to these posterior lumbar supporting structures can lead to atrophy of paraspinal muscles which caused trunk extensor weakness and possibly failed-back surgery syndrome and segmental instability ${ }^{(5)}$. In particular, spinal instability has been implicated as a cause of surgical failures, because wide decompression significantly alters spinal anatomy and biomechanics, thus prompting many surgeons to perform fusion procedures as an adjuvant treatment for lumbar stenosis. The frequency of fusion surgery has been steadily increasing in the treatment of degenerative lumbar stenosis despite numerous concerns ${ }^{(6)}$.In recent years limited opening in the spinal canal had increased in popularity. Single level or multilevel bilateral fenestration procedures constitute the major 
alternative to decompressive laminectomy for the treatment of multilevel lumbar spinal stenosis that preserved the posterior supporting structure ${ }^{(7)}$. In 1991 McCulloch modified microsurgical fenestration as described by Young $\boldsymbol{e t}$ al. and devised microscopic bilateral decompression through a unilateral approach as a less invasive technique ${ }^{(8)}$.

Implantation with a minimally invasive interspinous spacer is an alternative treatment option for patients with mild to moderate neurogenic intermittent claudication secondary to Lumbar Spinal Stenosis. Although use of interspinous spacers dates back to the 1950s, frequent dislodgements caused these devices to largely fall out of favor until the last decade ${ }^{(9)}$. Micro-decompression techniques may effectively reduce unnecessary tissue damage, and therefore, decrease the incidence of the complications. Fenestration with minimal soft tissue dissection and limited bone removal instead of extensive laminectomy to prevent subsequent lumbar instability has become widely accepted for the treatment of spinal stenosis. In these procedures, however, bi- or unilateral paraspinal muscles are detached from the spinous process and this may cause postoperative atrophy of paraspinal muscles ${ }^{(10)}$.

In 2005, first performed a new lumbar laminectomy procedure for LCS in which the exposure technique that was designed for cervical canal decompression reported by Shiraishi was modified. The new procedure, LSPSL, involves exposure of the lamina by longitudinally splitting the spinous process into two halves, leaving its muscular and ligamentous attachments undisturbed, and followed by laminotomy with minimal muscle dissection from the lamina. This procedure allows for better exposure of intraspinal nerve tissues comparable with conventional laminectomy, while minimizing damage to posterior supporting structures (5).

\section{AIM of the WORK}

This study aimed to evaluate the efficacy of technique of spinous process splitting approach in management of lumbar canal stenosis.

\section{PATIENTS AND METHODS}

This study included 20 cases who underwent minimally invasive spinous process splitting approach for lumbar canal stenosis. The work was done on the patients came to outpatient clinic and

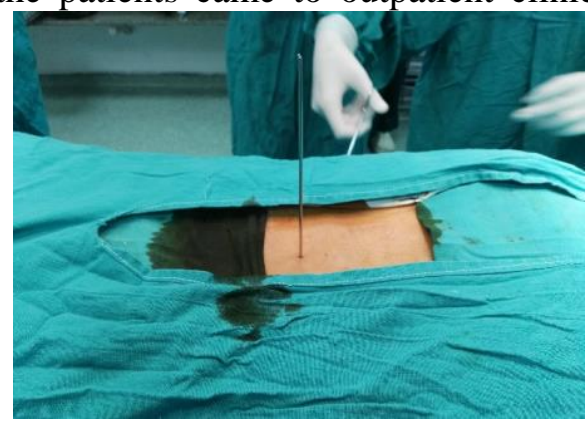

admitted in Orhthopedic Department of Al-Azhar University Hospitals and they were followed up in outpatient clinic.

Inclusion criteria: age: 18 years up to 70 years, patient with symptomes and signs of lumbar canal stenosis, either discogenic or degenerative stenosis, patient with LCS who was not respond to conservative treatment, or physical therapy rehabilitation for six months.

Exclusion criteria: extremes of age(younger than 18 years old and older than 70 years), patient with symptoms and signs of lumbar canal stenosis due other spine issues as spondylolithesis, tumors, post vertebral fracture and infection, patient who was not receive medical treatment or physical therapy rehabilitation less than six months and patients with other causes of neuropathic pain.

\section{Operative procedure}

Anesthetic technique: all patients were received general anesthesia with endotracheal intubation.Surgical technique of minimally invasive spinous process splitting approach in management of lumbar canal stenosis. We described the technique for one level L4-5 decompression performed via spinous process splitting.

Positioning: the patient was placed in prone position with slight kyphosis that is be better for surgical decompression. Patients were laid on cushioned metal spinal frame (Hall frame) allowing a recombinant and lax abdomen.

Exposure: after sterilization and draping, a routine longitudinal midline skin incision opposite to the affected level as identified on lateral fluoroscopy marked by kirchner wire or a needle. A posterior midline skin incision was made between the L-3 and L-5 spinous processes to expose the tip of L-4 spinous process. The L-4 spinous process was split longitudinally in the middle using a high speed drill running a fine 2-mm diamond-tipped burr; the structure was then divided at its base from the L-4 lamina, leaving the bilateral paraspinal muscles attached to the lateral aspect of the split spinous process. The supra- and interspinous ligaments between L3-4 and L4-5 were also split longitudinally using a scalpel. The muscles attached to the L-4 lamina were gently dissected using an elevator. Ample working space for laminectomy was obtained by retracting the split spinous process laterally together with its attached paraspinal muscles.

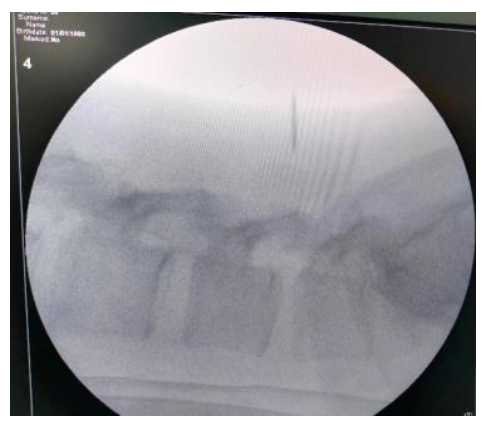

Figure 1: identification of the affected level by the lateral fluoroscopy image 

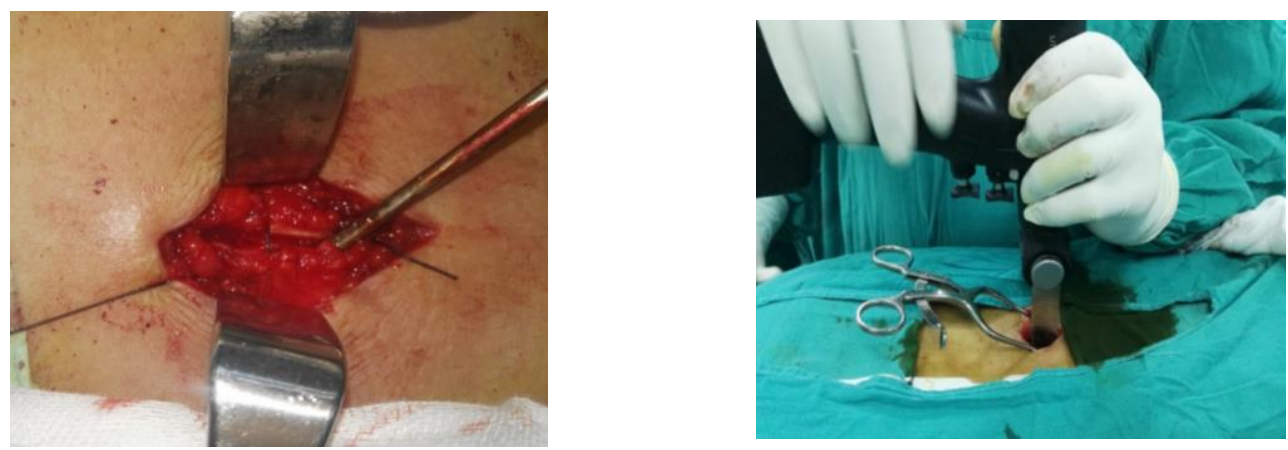

Figure 2: splitted spinus process by saw

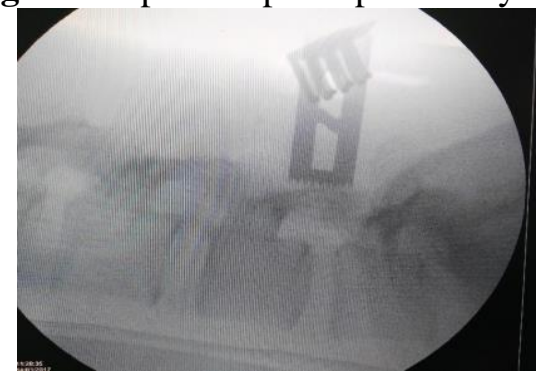

Figure 3: fluoroscopic image for splitting spinous process by saw
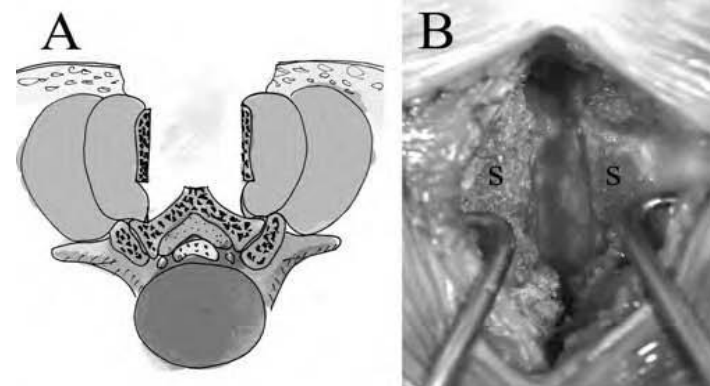

Figure 4: intraoperative photographs, and radiographs depicting the technique for one-level L4-5 decompression after L-4 spinous process splitting. A and B

\section{Decompressive Procedure:}

The L-4 lamina and the cephalad half of the L-5 lamina were removed using a highspeed drill; the L4-5 ligamentum flavum was then excised in the L4-5 interspace. The ligamentum flavum beneath the anterior aspect of the L-5 lamina was removed by using a small curved curette or a fine oblique Kerrison rongeur. If the working space and visualization for decompression are inadequate, the medial one third of the L4-5 facet joint was removed to widen the operative space. Thus, good access to the lateral recesses and the entry zone of the intervertebral foramina was obtained. In obese patients the surgical microscope was used as it is when adhesion between the nerve tissues and surrounding tissues exists. After the affected nerve roots and the thecal sac were successfully decompressed, each half of the split L-4 spinous process was reapproximated by using a strong nonabsorbable suture (Figs. 76C and D).

\section{Post-operative Management:}

\section{1- Clinical evaluation:}

Postoperative clinical evaluation was done for all patients through the Visual Analog Score (VAS) and Oswestry Disability Index (ODI) at 6 weeks, 6 months and one year (in most cases).

\section{Radiological evaluation:}

Postoperative plain X-rays were obtained in the second day postoperative, then after 6 months. MRI was done only for the patients with residual pain or those showed no improvement.

\section{Statistical Methodology}

Chi-square tests and analyses of variance were used to compare the baseline characteristics of the cases Age was analyzed as a discrete variable while sex, was categorized as male/female.The main outcome measure was pain intensity(Back pain and leg pain) over a twelve-month period. Other outcome measures were: duration of operation, length of hospitalstay and the overall effectiveness of the treatment was assessed as using ODI.

\section{RESULTS}

Table 1: description of pre-operative X-ray of the studied patients

\begin{tabular}{|l|l|c|}
\hline \multicolumn{2}{|c|}{ Variables } & $\begin{array}{c}\text { Studied patients }(\mathbf{N}= \\
\text { 20) }\end{array}$ \\
\hline $\begin{array}{l}\text { Pre- } \\
\text { operative } \mathrm{X}- \\
\text { ray }\end{array}$ & $\mathbf{L 3 / 4}$ & $4(20 \%)$ \\
\cline { 2 - 3 } & $\mathbf{L 4 / 5}$ & $10(50 \%)$ \\
\cline { 2 - 3 } & $\mathbf{L 5 / S 1}$ & $6(30 \%)$ \\
\hline
\end{tabular}


This table showed the description of pre-operative X-ray in the studied patients. 4 patients (20\%) was L3/4, 10 patients (50\%) were L $4 / 5$ and 6 patients (30\%) were L5/S1.

Table 2: description of pre-operative MRI of studied patients

\begin{tabular}{|l|l|c|}
\hline \multicolumn{2}{|c|}{ Variables } & Studied patients (N = 20) \\
\hline $\begin{array}{l}\text { Pre- } \\
\text { operative X- } \\
\text { ray }\end{array}$ & L3/4 & $4(20 \%)$ \\
\cline { 2 - 3 } & $\mathbf{L 4 / 5}$ & $10(50 \%)$ \\
\cline { 2 - 3 } & L5/S1 & $6(30 \%)$ \\
\hline
\end{tabular}

This table showed the description of pre-operative MRI in the studied patients. 4 patients (20\%) was L3/4, 10 patients (50\%) were L4/5 and 6 patients (30\%) were L5/S1.

Table 3: description of Leg back ratio of studied patients

\begin{tabular}{|c|c|c|}
\hline \multicolumn{2}{|c|}{ Variables } & Studied patients $(\mathrm{N}=20)$ \\
\hline \multirow{4}{*}{$\begin{array}{l}\text { Leg back } \\
\text { ratio }\end{array}$} & $40 / 60$ & $2(10 \%)$ \\
\hline & $50 / 50$ & $1(5 \%)$ \\
\hline & $60 / 40$ & $9(45 \%)$ \\
\hline & $70 / 30$ & $8(40 \%)$ \\
\hline
\end{tabular}

This table showed the description of Leg back ratio in the studied patients. 2 patients $(10 \%)$ were $40 / 60,1$ patient $(5 \%)$ was $50 / 50,9$ patients $(45 \%)$ were $60 / 40$, and 8 patients (40\%) were 70/30.

Table 4: description of level of operation in studied patients

\begin{tabular}{|l|l|c|}
\hline \multicolumn{2}{|c|}{ Variables } & Studied patients (N = 20) \\
\hline \multirow{2}{*}{$\begin{array}{l}\text { Level of } \\
\text { operation }\end{array}$} & $\mathbf{L 3 / 4}$ & $4(20 \%)$ \\
\cline { 2 - 3 } & $\mathbf{L 4 / 5}$ & $10(50 \%)$ \\
\cline { 2 - 3 } & $\mathbf{L 5 / S 1}$ & $6(30 \%)$ \\
\hline
\end{tabular}

This table showed the description of level of operation in the studied patients. 4 patients $(20 \%)$ were L3/4, 10 patients (50\%) were $\mathrm{L} / 5 / 5$ and 6 patients (30\%) were $\mathrm{L} 5 / \mathrm{S} 1$.

Table 5: comparison between pre-operative and post-operative VAS for back and leg

\begin{tabular}{|l|l|c|c|c|}
\hline \multicolumn{2}{|c|}{ VAS } & $\begin{array}{c}\text { Pre- } \\
\text { operative } \\
(\mathbf{N}=20)\end{array}$ & $\begin{array}{c}\text { Post- } \\
\text { operative } \\
(\mathbf{N}=20)\end{array}$ & P-value \\
\hline \multirow{2}{*}{ Back } & Mean & 7.05 & 1.3 & \multirow{2}{*}{$<$} \\
\cline { 2 - 4 } & \pm SD & 0.83 & 0.66 & $\mathbf{0 . 0 0 1 *}$ \\
\hline \multirow{2}{*}{ Leg } & Mean & 9.1 & 1.7 & $<$ \\
\cline { 2 - 4 } & \pm SD & 0.64 & 0.98 & $\mathbf{0 . 0 0 1 *}$ \\
\hline
\end{tabular}

*: p-value $<0.001$ is considered highly significant.

This table showed highly statistical significant difference ( $p$-value $<0.001$ ) between pre-operative and post-operative VAS for back and leg.
Table 6: comparison between pre-operative ODI\% and 1 day post-operative ODI\% in the studied patients

\begin{tabular}{|c|c|c|c|c|}
\hline & & $\begin{array}{c}\text { Pre- } \\
\text { operative } \\
(\mathbf{N}=\mathbf{2 0})\end{array}$ & $\begin{array}{c}1 \text { day Post- } \\
\text { operative } \\
(\mathrm{N}=20)\end{array}$ & $\begin{array}{c}\text { P- } \\
\text { value }\end{array}$ \\
\hline \multirow{2}{*}{ ODI\% } & Mean & 71.2 & 13.4 & \multirow{2}{*}{$\begin{array}{c}< \\
0.001 *\end{array}$} \\
\hline & \pm SD & 5.75 & 7.65 & \\
\hline
\end{tabular}

*: p-value $<0.001$ is considered highly significant.

This table showed highly statistical significant difference ( $p$-value < 0.001 ) between pre-operative ODI\% and 1 day post-operative ODI $\%$ in the studied patients.

Table 7: comparison between pre-operative ODI\% and 3 month post-operative ODI\% in the studied patients

\begin{tabular}{|c|c|c|c|c|}
\hline & & $\begin{array}{c}\text { Pre- } \\
\text { operative } \\
(\mathbf{N}=20)\end{array}$ & $\begin{array}{c}3 \text { month } \\
\text { Post- } \\
\text { operative } \\
(\mathrm{N}=20)\end{array}$ & $\begin{array}{c}P- \\
\text { value }\end{array}$ \\
\hline \multirow{2}{*}{ ODI\% } & Mean & 71.2 & 9.4 & \multirow{2}{*}{$\begin{array}{c}<< \\
0.001\end{array}$} \\
\hline & \pm SD & 5.75 & 4.68 & \\
\hline
\end{tabular}

*: p-value $<0.001$ is considered highly significant.

This table showed highly statistical significant difference ( $p$-value < 0.001 ) between pre-operative ODI\% and 3 month post-operative ODI $\%$ in the studied patients.

Table 8: comparison between pre-operative ODI\% and 6 month post-operative ODI\% in the studied patients

\begin{tabular}{|c|c|c|c|c|}
\hline & & $\begin{array}{c}\text { Pre- } \\
\text { operative } \\
(\mathbf{N}=\mathbf{2 0})\end{array}$ & $\begin{array}{l}6 \text { month } \\
\text { Post- } \\
\text { operative } \\
(\mathrm{N}=20)\end{array}$ & $\begin{array}{c}P \text { - } \\
\text { value }\end{array}$ \\
\hline \multirow{2}{*}{ ODI\% } & Mean & 71.2 & 9.4 & \multirow{2}{*}{$\begin{array}{c}< \\
0.001 *\end{array}$} \\
\hline & \pm SD & 5.75 & 4.82 & \\
\hline
\end{tabular}

*: p-value $<0.001$ is considered highly significant.

This table showed highly statistical significant difference ( $p$-value $<0.001$ ) between pre-operative ODI\% and 6 month post-operative ODI\% in studied patients.

Table 9: description of blood loss studied patients

\begin{tabular}{|c|l|c|}
\hline \multicolumn{2}{|c|}{ Variables } & $\begin{array}{c}\text { Studied patients }(\mathbf{N}= \\
\mathbf{2 0})\end{array}$ \\
\hline \multirow{4}{*}{ Blood loss (cc) } & Mean & 168.3 \\
\cline { 2 - 3 } & \pm SD & 45.3 \\
\cline { 2 - 3 } & Min & 100 \\
\cline { 2 - 3 } & Max & 250 \\
\cline { 2 - 3 } & Range & $100-250$ \\
\hline
\end{tabular}

This table showed the description of blood loss in the studied patients. The mean blood loss in studied patients was $168.3 \pm 45.3 \mathrm{cc}$ with minimum loss of $100 \mathrm{cc}$ and maximum loss of $250 \mathrm{cc}$ (range $100-250$ ). 
Table 10: description of hospital stay in the studied patients

\begin{tabular}{|l|l|c|}
\hline \multicolumn{2}{|c|}{ Variables } & $\begin{array}{c}\text { Studied patients (N = } \\
\mathbf{2 0})\end{array}$ \\
\hline \multirow{4}{*}{$\begin{array}{l}\text { Hospital } \\
\text { (day) }\end{array}$} & Mean & 2.5 \\
\cline { 2 - 3 } & \pm SD & 1.4 \\
\cline { 2 - 3 } & Min & 2 \\
\cline { 2 - 3 } & Max & 5 \\
\cline { 2 - 3 } & Range & $2-5$ \\
\hline
\end{tabular}

This table showed the description of hospital stay in studied patients. The mean hospital stay in studied patients was $2.5 \pm 1.4$ days with minimum stay of 2 days and maximum stay of 5 days (range $2-5$ ).

Table 11: description of operative time in studied patients

\begin{tabular}{|l|l|c|}
\hline \multicolumn{2}{|c|}{ Variables } & $\begin{array}{c}\text { Studied patients }(\mathbf{N}= \\
\mathbf{2 0})\end{array}$ \\
\hline \multirow{4}{*}{$\begin{array}{c}\text { Operative } \\
\text { time(min) }\end{array}$} & Mean & 108.3 \\
\cline { 2 - 3 } & \pm SD & 13.4 \\
\cline { 2 - 3 } & Min & 90 \\
\cline { 2 - 3 } & Max & 130 \\
\cline { 2 - 3 } & Range & $90-130$ \\
\hline
\end{tabular}

This table showed the description of operative time in the studied patients. The mean operative time in studied patients was $108.3 \pm 13.4$ min with minimum time of 90 min and maximum time of 130 min (range $90-$ 130).

\section{DISCUSSION}

Lumbar canal stenosis is a common diagnosis in ageing individuals and the rates of surgery have risen all over the world. In metaanalysis decompressive surgery was shown to be a successful way of treatment in relieving symptoms of lumbar spine stenosis ${ }^{(11)}$.

In long- term outcomes, surgically treated patients showed greater improvement in back pain and lower limb symptoms than nonsurgically treated patients ${ }^{(12)}$.

For years, the surgical treatment of degenerative lumbar canal stenosis has been wide laminectomy, which allowed decompression of the neural elements by deroofing the spinal canal. However, the success rate of this procedure was only about $64 \%$, this has been attributed to local tissue trauma, and postoperative spinal instability, which has led to frequent surgical failures and dramatic increase in lumbar fusion surgery ${ }^{(6)}$.Increasing knowledge of the anatomy and pathology, coupled with high-resolution imaging, allowed a precise localization of nerve compression, which usually occurs at the level of the intervertebral space and the hypertrophied ligamentum flavum. A study proposed more tailored and less invasive techniques in the treatment of degenerative lumbar canal stenosis. In particular, bilateral and unilateral laminotomy for bilateral decompression have been described ${ }^{(13)}$.

Our current study was a non - randomized prospective reviewing the outcome of minimally invasive spinus process splitting approach in management of spinal canal stenosis, as a less invasive surgery to decompress the stenotic canal.

\section{Evaluation of postoperative data:}

\section{1- VAS for Low Back Pain:}

A highly significant difference was found regarding change in VAS LBP $(7.05 \pm 0.83$ vs $1.3 \pm 0.66$ ), with higher mean change preoperative and postoperative that could be related in part to the less destruction of the spinous process and minimal bony work done. Back muscles provide the majority of resistance to external load in stabilizing the lumbar spine. Detachment of these muscles from the spinous processes and vertebral arches with subsequent wide retraction has been associated with muscle denervation and atrophy. Additionally, the spinous processes and the interspinous ligaments act as a posterior tension band. A biomechanical study showed that spinous processes and interspinous ligaments resist significant force towards the end of the range of flexion and provide a modest contribution to the force of back muscles during extension. Thus, minimising disruption of back muscles and avoiding removal of spinous processes, vertebral arches and interspinous ligaments can possibly reduce muscle weakness, low-back pain, accelerated spondylosis and surgically induced instability ${ }^{(14)(6)}$.

\section{VAS for Leg Pain:}

There was also a significant difference between preoperative and postoperative. The VAS Leg pain was decreased $(6 \pm 0.7$ Vs $5.05 \pm 1.1)$. This indicates that MISPSA achieved an efficient way for roots decompression that was.

\section{Oswestry Disability Index (ODI):}

There was a highly significant difference found regarding change in ODI (Pre-operative ODI - ostoperative ODI) $(71.2 \pm 5.75$ vs $13.4 \pm 7.65)$.

\section{Blood loss:}

There was a statistically significant decrease regarding intraoperative blood loss. Minimally invasive spinus process splitting approach show low mean blood loss $(168.3 \pm 45.3)$ if compared to traditional laminectomy. 


\section{Operation time:}

There was significant decreased duration of surgery in MISPSA (108.3 \pm 13.4$)$.

\section{Postoperative hospital stay:}

There was a significant difference with a lower Mean Hospital stay in MISPSA (2.5 \pm 1.9$)$.

\section{Complications:}

In our study, the rate of complications in our technique was dural tear in one case, and serous fluid discharge for the wound in another case and this was little complication than conventional method.

\section{CONCLUSION}

MISPSA with less bony work and preservation of the spinous process, supraspinous and interspinous ligaments seemed to be a safe and effective procedure in management of lumbar canal stenosis. It also showed better improvement in the clinical outcome at the 12-month follow up interval.

\section{REFERENCES}

1. Lohman CM, Tallroth $\mathrm{K}$, Kettunen JA et al. (2006): Comparison of radiological signs and clinical symptoms of spinal stenosis. Spine, 31: 1834-1840.

2. Kalichman L, Cole R, Kim DH, Li L et al.(2009): Spinal stenosis prevalence and association of symptoms: the framingham study. Spine J. ,9(7): 545-550.

3. Domagoj C and Charles LB(1997): Posterior lumbar interbody fusion in the treatment of symptomatic spinal stenosis. Neurosurg. Focus, 3(2): 5-12.

4. Palmer $S$, Turner $R$ and Palmer $R(2002)$ : Bilateral decompression of lumbar spinal stenosis, involving a unilateral approach with microscope and tubular retractor system. J. Neurosrg.,2: 213-217.
5. Watanabe K, Hosoya T, Shiraishi T et al.(2005): Lumbar spinous process splitting laminectomy for lumbar canal stenosis. Technical note. J. Neurosurg. Spine, 3: 405-408.

6. Korovessis P, Papazisis Z, Koureas $G$ and Lambiris E(2004): Rigid, semirigid versus dynamic instrumentation for degenerative lumbar spinal stenosis: a correlative radiological and clinical analysis of short-term results. Spine, 29:735-742.

7. Young S, Veerapen $R$ and O'Loaire(1988): Relief of lumbar canal stenosis using multilevel subarticular fenestration as alternative to wide laminectomy, preliminary report. Neurosurgery, 23: 628-634.

8. McCulloch JA(1991):Microsurgical spinal laminotomies.In: The Adult Spine: Principles and Practice. Frymoyer J.W., Raven Press, Ltd. New York.

9. Sobottke R, Schluter-Burst $K$, Kaulhausen $T$ et al.(2009): Interspinous implants (X-Stop, Wallis, Diam) for treatment of LSS: is there a correlation between radiological parameters and clinical outcome? European Spine Journal, 18(10): 1494-1503.

10.Guiot BH, Khoo LT and Fessler RG(2002): A minimally invasive technique for decompression of the lumbar spine. Spine, 27(4):432-440.

11. Turner JA, Ersek M, Herron L and Deyo R(1992): Surgery for lumbar spinal stenosis. Spine, 17(1):1-8.

12. Anjarwalla NK, Brown LC and McGregor A H(2007): The outcome of spinal decompression surgery 5 years on. Eur. Spine J., 16:1842-1847.

13. Thome C, Zevgaridis D, Leheta $O$, Bazner H, PocklerSchoniger $\mathbf{C}$, Wohrle $J$ and Schemiedek $P$ (2005): Oucome after lessinvasive decompression of spinal stenosis: a randomized comparison of unilateral laminotomy, Bilateral Laminotomy and laminectomy. J. Neurosurg. Spine, 3: 129-141.

Bresnahan L, Ogden AT, Natarajan RN and Fessler RG(2009): A biomechanical evaluation of graded posterior element removal for treatment of lumbar stenosis: comparison of a minimally invasive approach with two standard laminectomy techniques. Spine, 34:1723. 